\title{
EL INTERÉS JURÍDICO DE LAS PRETENSIONES RELATIVAS A LA TENENCIA O AL RÉGIMEN DE VISITAS DE LOS ANIMALES DOMÉSTICOS
}

\author{
Crístian Oró Martínez \\ Investigador Postdoctoral de Derecho Internacional Privado \\ Universitat Autònoma de Barcelona \\ cristian.oro@uab.cat
}

1. Estas breves reflexiones tienen por objeto dos sentencias relativamente recientes, que se ocupan desde perspectivas distintas $-\mathrm{y}$ con resultados hasta cierto punto disímiles, como veremos- de una cuestión de indudable interés y actualidad: a saber, la posibilidad de solicitar judicialmente, en caso de crisis matrimonial o de ruptura de una pareja de hecho, regímenes de tenencia o custodia compartida, o bien regímenes de visitas, respecto de animales de compañía. Un análisis que, más específicamente, se vehiculará desde la perspectiva de la existencia o inexistencia de interés jurídico suficiente en tales pretensiones, a efectos de justificar su acceso a la tutela de nuestros órganos jurisdiccionales. El examen de dichas cuestiones se llevará a cabo al hilo de la sentencia del Juzgado de Primera Instancia núm. 2 de Badajoz de 7 de octubre de 2010 (http://www.derechoanimal.info/bbdd/Documentos/806.doc) y de la sentencia de la Audiencia Provincial de León (Sección $1^{\text {a }}$ ) de 25 de noviembre de 2011 (http://www.derechoanimal.info/bbdd/Documentos/965.pdf).

2. La primera de ellas, la sentencia del JPI de Badajoz, constituye una resolución de notable interés por varios motivos. Por una parte, porque deriva de una acción que tiene por única finalidad la de establecer el régimen de tenencia de un perro, siendo así que lo habitual es que estas cuestiones vengan tratadas junto con otras cuestiones, en el marco de la regulación de una crisis matrimonial. Pero es que, además, en este supuesto la acción trae causa de la ruptura de una pareja de hecho, de modo que la configuración jurídica deviene algo más compleja, obligando al juez a realizar una breve incursión en el régimen jurídico de las parejas de hecho (FJ segundo), así como unas interesantes consideraciones sobre el régimen jurídico de la propiedad de los animales (FJ primero). Asimismo, como ya se ha apuntado, la resolución se detiene también en el análisis de la existencia de un interés jurídico suficiente, en una acción de este tipo, para justificar que el objeto del procedimiento sea merecedor de tutela jurisdiccional en el sentido exigido por el art. 5 de la Ley de Enjuiciamiento Civil (FJ tercero), recurriendo para ello incluso a una leyenda de los indios norteamericanos para ilustrar la estrecha relación entre el ser humano y el perro desde el momento mismo de la creación del mundo.

Se trata, en definitiva, de una sentencia que se ocupa de numerosas cuestiones que suscitarán sin duda el interés del lector -no necesariamente jurista- amante de los animales. Con todo, nos centraremos aquí en unas consideraciones más breves, motivo por el cual remitimos a los interesados a la lectura de la propia sentencia (así como del comentario de $\mathrm{M}^{\mathrm{a}}$ Dolores Díaz- 
Ambrona Bardají, "Las mascotas en las rupturas de parejas de hecho", Actualidad Civil, $\mathrm{n}^{\circ}$ 20, del 16 al 30 de noviembre de 2011, pp. 2287 y ss.; La Ley 17404/2011).

3. Los hechos de los que deriva la sentencia del JPI de Badajoz pueden resumirse como sigue. En 1996 empezaron a convivir como pareja de hecho quienes posteriormente fueron demandante y demandado en este asunto. En 2001, los entonces convivientes encontraron un perro, que pasaron a poseer y compartir conjuntamente. La pareja de hecho se rompió en 2005, pero hasta mediados de 2009 siguieron compartiendo el perro, momento en el que el demandado se quedó con la posesión exclusiva del perro.

Frente a ello, la demandante decidió acudir a la justicia para lograr la posesión compartida del perro, y desvirtuar de este modo la alegación del demandado según la cual la mascota era un bien privativo suyo. Parecería que el demandado fundamentaba dicha alegación en el hecho de que había sido él quien, en Mérida y en el año 2001, había encontrado al perro. Sin embargo, el JPI no acepta tal alegación, sino que concluye que el animal había pasado a formar parte integrante de una comunidad de bienes fundada por los convivientes durante sus años de cohabitación.

A tal efecto, el órgano judicial se remite a la jurisprudencia del Tribunal Supremo en virtud de la cual la convivencia more uxorio no comporta la aplicación de la normativa sobre matrimonio -en especial, la relativa a sus efectos patrimoniales-, pero sí puede en cambio llevar a la constatación de la existencia de una comunidad de bienes. Dicha comunidad de bienes, con todo, no deberá entenderse creada de forma automática por la mera convivencia, sino que habrá de deducirse de la voluntad de los convivientes, manifestada bien expresamente, o bien tácitamente mediante hechos concluyentes que evidencien una voluntad inequívoca de hacer comunes todos o algunos de los bienes adquiridos durante la convivencia. Así, el JPI afirma que in casu no cabe duda de que, durante su convivencia, los actuales litigantes fundaron no sólo una comunidad de vida, sino también una comunidad de bienes, según se desprende de una anterior sentencia del JPI núm. 5 de Badajoz en la que se hizo constar que durante la convivencia de esta pareja sus patrimonios no permanecieron separados, sino que se confundieron. Según la resolución que comentamos, en dicha comunidad de bienes vino a integrarse también el perro, extremo confirmado por la existencia de dos cartillas veterinarias, una a nombre de cada uno de los convivientes, así como de múltiples fotografías que evidenciarían la posesión y conservación compartida del perro, y con ello, el carácter de bien común del animal.

Llegados a este punto, la tenencia compartida -o custodia compartida, nos atreveríamos a matizar- es la solución aceptada por el juez. Puesto que la demandante y el demandado deben ser considerados como copropietarios del perro, y el mismo es evidentemente indivisible, no cabe sino dictaminar su disfrute compartido. El juez descarta la otra opción viable -a saber, la extinción de la comunidad mediante la adjudicación del perro a uno de los dueños, con obligación de indemnizar al otro - por no haber sido pedida por las partes. Esta tenencia temporal se concreta en períodos de tiempo equivalentes para ambos propietarios, por lo que el perro deberá pasar a estar seis meses en poder de cada uno, empezando por la demandante, que es quien llevaba más tiempo privada de la tenencia del animal.

4. Como hemos apuntado, esta tenencia compartida es equiparable, en los términos en que está formulada, a una custodia compartida del animal, especialmente si tomamos en 
consideración el delicado tratamiento que el juzgador hace de la cuestión de la propiedad de los animales y el régimen jurídico de su posesión. En efecto, el juez va mucho más allá del análisis del régimen de propiedad y posesión de los bienes, como pone de manifiesto la integridad del FJ tercero de la resolución que analizamos. En efecto, la digresión sobre el papel del perro en la vida de los seres humanos es de mucha mayor entidad que el estricto análisis del interés jurídico de la pretensión, cuestión a la que se dedican los últimos párrafos de dicha sección de la sentencia. De este modo, y en contraste con cierta jurisprudencia que puntualmente ha sostenido lo contrario, la resolución deja bien sentado que este tipo de reclamaciones deben poder ser llevadas ante los tribunales, con un análisis obviamente y necesariamente jurídico, pero que no olvida subrayar el trasfondo filosófico subyacente en esta cuestión -el del carácter no sólo de objeto de derechos, sino también de sujetos de derechos que puede predicarse de los animales-, y que nos permitimos reproducir aquí: "Que sí deben tener acceso jurisdiccional los conflictos que puedan suscitarse por razón de la tenencia de un animal compartido es conclusión, por otra parte, que se alcanza con solo advertir que no dejan de ser bienes apropiables y, por ende, objeto de derechos. Y todo ello sin necesidad de acudir aquí a esas tesis filosóficas que, yendo más allá y con buena dosis de razón, buscan convencernos de que los animales son seres sensibles e independientes, no simples objetos cuya existencia se reduce a satisfacer nuestros intereses humanos".

5. Lo que acabamos de exponer contrasta con la resolución de la AP de León de la que nos ocupamos a continuación. Esta sentencia trae causa de un recurso de apelación interpuesto contra una sentencia de divorcio dictada por el JPI núm. 2 de León el 20 de mayo de 2011, en la que el órgano de primera instancia rechazó pronunciarse sobre la tenencia o custodia y el régimen de visitas de un perro. Debe señalarse que el pacto sobre la tenencia del perro había sido incluido por las partes en el convenio regulador del divorcio, por lo que la cuestión revisada en apelación es si el órgano a quo podía negarse a incluirlo en la sentencia de divorcio.

En efecto, en el convenio regulador constaba un pacto en virtud del cual el ahora apelante pasaría con el perro dos fines de semana al mes, el primero y el tercero, así como sus períodos de vacaciones, mientras que su ex esposa tendría al perro el resto del tiempo. Así pues, como se ve, se trata de constituir un verdadero régimen de visitas o comunicaciones con un perro para uno de sus copropietarios en caso de divorcio, tal como de hecho reconoce la propia AP en el FJ segundo de su resolución. Sin embargo, la duda que surge no es si cabe un derecho de visitas respecto de un animal, sino más bien si las controversias relativas a tal derecho tienen la suficiente relevancia e interés jurídico como para ser acreedoras de tutela jurisdiccional en un proceso de familia, a la hora de establecer las medidas reguladoras de la crisis.

Así, la AP reconoce que cabe constituir regímenes de visitas respecto de perros u otros animales: de hecho, reconoce el carácter habitual de tales pactos en el marco de los convenios reguladores en caso de separación o divorcio. Sin embargo, la AP resta inmediatamente trascendencia jurídica a este tipo de acuerdos, al afirmar que "lo razonable jurídicamente es que tales acuerdos, igual que los alcanzados en este supuesto en el momento del juicio, tengan trascendencia entre las partes pero sin la cualidad de ejecutables en el proceso de familia". Para reforzar estos argumentos, el órgano jurisdiccional cita y hace suyos los términos de un auto de la AP de Barcelona de 5 de abril de 2006, en el que se afirma que "el sentido común, y la medida de lo que resulta razonable, aconsejan a las personas que no deben establecer 
litigios respecto a tales hipotéticos derechos que, aun estando recogidos contractualmente, trascienden de lo jurídico o, con más precisión, de lo jurídicamente exigible" (el destacado es nuestro). Por todo ello, la AP ratifica la decisión del JPI de no incluir el acuerdo sobre el régimen de visitas del perro en la sentencia de divorcio, añadiendo a continuación, eso sí, "sin perjuicio de la validez que [tal acuerdo] tiene entre los propietarios".

6. En resumen, y a modo de breve conclusión, resulta evidente que estamos ante dos sentencias que se ocupan de cuestiones similares, si bien las resuelven de modo discordante; y ello, aun cuando el fundamento de la resolución es prácticamente idéntico: la existencia o inexistencia de relevancia o interés jurídico, a efectos de acceso a los tribunales, de las pretensiones relativas a la tenencia, custodia o régimen de visitas de animales de compañía. Entendemos que, por su fundamentación y por el análisis exhaustivo de las cuestiones suscitadas en este tipo de acciones, es preferible la solución dada por la sentencia del JPI de Badajoz. Pero sea como fuere, lo obvio es que la seguridad jurídica requiere que estas notas discordantes desaparezcan de nuestro ordenamiento, y que se establezca de modo unívoco y definitivo cuál ha de ser la respuesta a la cuestión del interés jurídico del tipo de pretensiones de las que se ocupan las sentencias que hemos comentado brevemente. 